\title{
Knowledge and Prevalence of Family Planning Measures among Community People of Chisapani, Banke
}

\author{
Roy R $K^{1}$, Roy D K $K^{2}$, Bist $A^{3}$, Ghimire $S^{4}$
}

\begin{abstract}
Introduction: Global threat of increasing population has become a challenge to control. That's why Family planning is a strong matter of concern for most of the developing countries like Nepal. The first family planning service in Nepal was provided by Family Planning Association Nepal (FPAN) in 1959 to provide an Integrated Package of Essential Services (IPES) that includes comprehensive counselling; family planning and sexual health services; safe abortion services; HIV and AIDS and other sexually-transmitted infection (STI) services; gynaecological, prenatal, and post-natal care; and GBV care. Several studies reflect that increment in population is directly related to the level of education, low family income, and lack of awareness, strong cultural beliefs and many more. Especially, village areas of Nepal are deprived of Family Planning services and measures due to lack of coverage and other facilities. Thus knowledge regarding Family planning and contraception needs to be accessed and hence a village in Chisapani, Banke district of Nepal was chosen for this study. Objectives: The overall objectives of our study were to access the knowledge regarding Family planning, to access the practise of Contraceptive measures and to find out the contraceptive prevalence rate (CPR) among community people of Chisapani village, Banke. Material and Method: A Cross-sectional descriptive study with population size of 410 community people was performed in Chisapani, Banke; starting from $18^{\text {th }}$ June to $2^{\text {nd }}$ September, 2018. A pre-tested questionnaire containing structural, semi-structural and open ended questions were made as data collection tool. All the people in this study were interviewed after receiving consent as an ethical clearance. Result: 393 out of 410 (i.e. 95.85\%) people in our study have known about Family planning via Mass Media (75.82\%). Only $70.48 \%$ people responded to have used any Contraceptive measure. Depo was found to be the most used measure (i.e. 54.87\%). $42.43 \%$ people have heard about emergency contraceptive pills but only $20.68 \%$ among them have ever used it. Conclusion: Though $95.85 \%$ of the respondents of our study had known about Family Planning however only $70.48 \%$ people have been using any of the contraceptive measures. Emergency contraceptive pills were used by only $20.68 \%$ of the respondents.
\end{abstract}

Key words: Contraception, depo-provera, family planning, knowledge, pills

\section{INTRODUCTION}

Global population has increased tremendously from 1 billion (1800 A.D) to 7.616 billion in 2018 A.D. at the rate of $1 \%$ per annum.Nepal being a developing country, the total population was 26,494,501 (Census 2011) which is increased than previous 2001 census $(23,151,423)$, which suggests an annual growth rate of $1.35 \%$. To control this day by day increasing population in the world and to improve the maternal and child health, the concept of family planning was set up in 1936 A.D. which was at first known as the Sex Hygiene and Birth Regulation Society. At that time, contraception was basic and unreliable.In Nepal, first family planning services was provided by Family Planning Association Nepal (FPAN), established in 1959 A.D. Currently it involves 37 districts with the objectives to providean Integrated Package of Essential Services (IPES)

\footnotetext{
1. Mr. Roshan Kumar Roy

2. Dr. D. K. Roy

3. Mr. A. Bist

4. Mr. S. Ghimire
}

Address for correspondence:

Mr. Roshan Kumar Roy

Department of Community Medicine

Nepalgunj Medical College, Chisapani, Banke

Email:link2roy@gmail.com that includes comprehensive counselling; family planning and sexual health services; safe abortion services; HIV/AIDS and other sexually-transmitted infection (STI) services; gynaecological, prenatal, and post-natal care; and Gender Based Violence (GBV) care. ${ }^{1}$ Family planning services are defined as "educational, comprehensive medical or social activities which enable individuals, including minors, to determine freely the number and spacing of their children and to select the means by which this may be achieved". ${ }^{2}$ This also includes the age at which she wishes to have them. "Contraception" is defined as the measures - Natural/Artificial to control pregnancy (Calendar, withdrawal, condom, pills, Depo, vasectomy, etc.).

NDHS (2016) suggests the Family planning coverage of any method to be $(53 \%)$, by modern methods $(43 \%)$ and $(10 \%)$ by traditional methods. $24 \%$ of the married women had unmet needs of Family planning services. ${ }^{3}$ Although Family planning being a priority program of the Government of Nepal; there is unmet demand for it due to reasons like lack of information, inconvenient or unsatisfactory services, fears about contraceptive side effects, and opposition from husband or relatives. Different data suggests that today, more than 300 million women in the 69 poorest countries use modern 
contraception due to which approximately 82 million unwanted pregnancies, 25 million unsafe abortion and 125,000 maternal deaths are averted annually ${ }^{4}$. As mentioned above, the contraceptive prevalence rate(CPR) is associated with lack of awareness, improper services, and unscientific believes which are more common in village of underdeveloped areas, so our study was conducted in Chisapani village of Banke district.

\section{MATERIAL AND METHOD}

This study was conducted based on descriptive cross sectional design, data was collected only once and there was no follow up done. This study was basically focused on assessing the knowledge and practice of Family Planning among the community members of Chisapani, Banke. Villagers were interviewed using questionnaire having structured and semistructured also open ended questions. 410 members of Chisapani village were selected as study population. Collected primary data were later tabulated and analysed using cross tabulation and descriptive calculations. Study started in $18^{\text {th }}$ of June 2018, validity and reliability of questionnaire were checked by interviewing 30\% of real population. Nepali language was used in questionnaire for better response. All the collected information were assessed using MS-EXCEL and SPSS version 22 for descriptive analysis. Informed consent were taken from each member of the study population. Analysed data were thus presented in the form of tables and charts and interpreted accordingly.

\section{RESULTS}

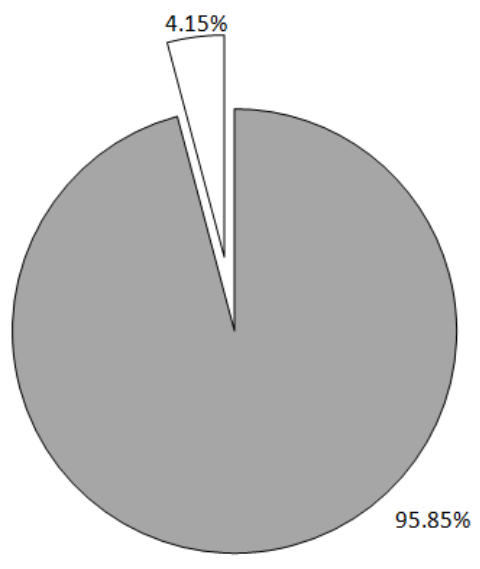

Figure 1: Knowledge of family planning

Pie Chart above shows that out of 410 respondents, 393(95.85\%) have heard about Family Planning while remaining $17(4.15 \%)$ have not heard.

\begin{tabular}{|c|l|c|c|}
\hline S.N & Media & Number & Percentage \\
\hline 1. & T.V/Radio & 298 & $75.82 \%$ \\
\hline 2. & Health workers & 282 & $71.75 \%$ \\
\hline 3. & Family friends & 98 & $24.13 \%$ \\
\hline 4. & Others & 42 & $10.68 \%$ \\
\hline
\end{tabular}

Table I: Source of information regarding family planning

Table above shows that highest number of respondents i.e. 298(75.82\%) have heard about Family Planning via T.V/Radio

\begin{tabular}{|c|l|c|c|}
\hline S.N & Measures & Number & Percentage \\
\hline & A.MODERN MEASURES & & \\
\hline 1. & Depo (Sangini) & 369 & $93.89 \%$ \\
\hline 2. & Pills & 325 & $82.69 \%$ \\
\hline 3. & Condom & 340 & $86.50 \%$ \\
\hline 4. & IUCD (Copper-T) & 321 & $81.67 \%$ \\
\hline 5. & Norplant & 312 & $79.38 \%$ \\
\hline & B.TRADITIONAL MEASURES & & \\
\hline 1. & Withdrawl method & 95 & $24.17 \%$ \\
\hline 2. & Calender method & 86 & $21.88 \%$ \\
\hline 3. & Abstinence & 93 & $23.66 \%$ \\
\hline & C. PERMANENT METHODS & & \\
\hline 1. & Male sterilization & 244 & $62.08 \%$ \\
\hline 2. & Female sterilization & 304 & $77.35 \%$ \\
\hline
\end{tabular}

Table II: Knowledge of family planning measures

The above table shows that maximum number of respondents had an idea about Depo-Provera injection, condom, and pills respectively.

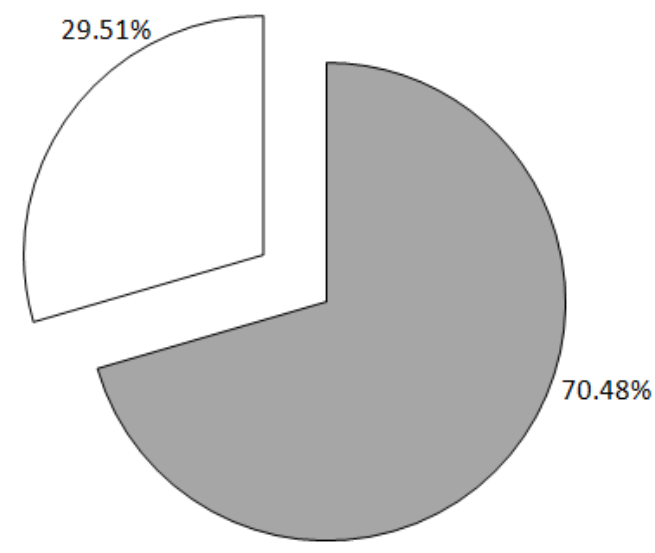

$\square$ Yes(277) $\square$ No(116)

Figure 2: Use of family planning measures

Pie Chart above shows that out of 410 respondents, 277(70.48\%) have used Family Planning measures while remaining $116(29.51 \%)$ have not used. 


\begin{tabular}{|c|l|c|c|}
\hline S.N & Measures & Number & Percentage \\
\hline & A.MODERN MEASURES & & \\
\hline 1. & Depo (Sangini) & 152 & $54.87 \%$ \\
\hline 2. & Pills & 74 & $26.71 \%$ \\
\hline 3. & Condom & 91 & $32.85 \%$ \\
\hline 4. & IUCD (Copper-T) & 16 & $5.70 \%$ \\
\hline 5. & Norplant & 26 & $9.38 \%$ \\
\hline & B.TRADITIONAL MEASURES & & \\
\hline 1. & Withdrawal method & 18 & $6.49 \%$ \\
\hline 2. & Calendar method & 06 & $2.16 \%$ \\
\hline 3. & Abstinence & 05 & $1.80 \%$ \\
\hline & C. PERMANENT METHODS & & \\
\hline 1. & Male sterilization & 14 & $5.05 \%$ \\
\hline 2. & Female sterilization & 25 & $9.02 \%$ \\
\hline
\end{tabular}

Table III: Use of family planning measures

The table shows that $152(54.87 \%)$ out of 277 have been using Depo (modern measure) for family planning.

\begin{tabular}{|c|l|c|c|}
\hline S.N & Reason & Number & Percentage \\
\hline 1. & Cheap in price & 20 & $7.22 \%$ \\
\hline 2. & Easily available & 79 & $28.51 \%$ \\
\hline 3. & Easy to use & 134 & $48.37 \%$ \\
\hline 4. & Prescribed by health workers & 31 & $11.19 \%$ \\
\hline 5. & Suggested by Family \& Friends & 17 & $6.13 \%$ \\
\hline 6. & Others & 82 & $29.60 \%$ \\
\hline
\end{tabular}

Table IV: Reasons for using particular family planning measures

Table above shows that highest number of respondents i.e. $134(48.37 \%)$ have answered Easy to use to the reason for using particular family planning measures.

\begin{tabular}{|c|l|c|c|}
\hline S.N & Reason & Number & Percentage \\
\hline 1. & Not needed till & 36 & $31.89 \%$ \\
\hline 2. & Planning to use & 22 & $18.96 \%$ \\
\hline 3. & Don't like using & 20 & $17.24 \%$ \\
\hline 4. & Others & 64 & $55.17 \%$ \\
\hline
\end{tabular}

Table V: Reasons for not using family planning measures

Table above shows that highest number of respondents i.e. $36(31.89 \%)$ have answered Not needed till to the reason for not using family planning measures

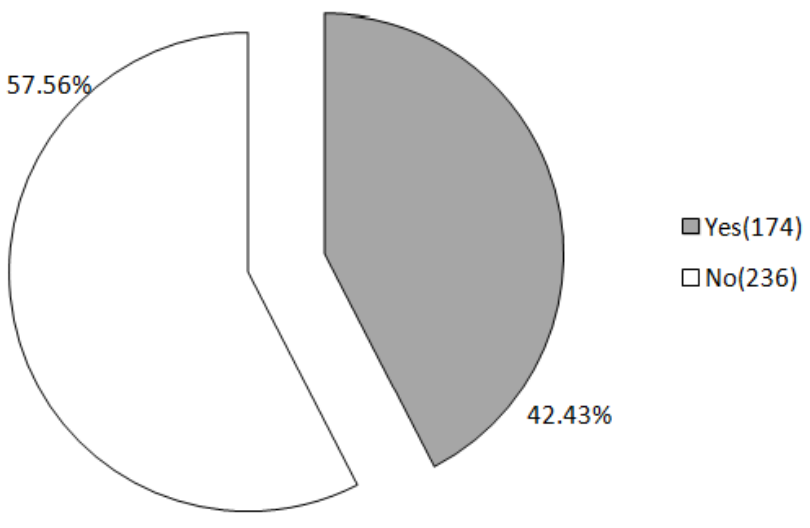

Figure 3: Knowledge regarding emergency contraceptives

Pie Chart above shows that out of 410 respondents, $174(42.43 \%)$ have knowledge regarding Emergency contraceptives while remaining $236(57.56 \%)$ have no knowledge about it.

\begin{tabular}{|c|l|c|c|}
\hline S.N & Reason & Number & Percentage \\
\hline 1. & Taken after sexual intercourse & 44 & $25.28 \%$ \\
\hline 2. & Better than other methods & 31 & $17.81 \%$ \\
\hline 3. & 72 hours pill & 121 & $69.54 \%$ \\
\hline 4. & Easy to use & 05 & $2.80 \%$ \\
\hline 5. & Others & 07 & $4.02 \%$ \\
\hline
\end{tabular}

Table VI: Knowledge regarding use of emergency contraceptives

Table above shows that highest number of respondents i.e. $121(69.54 \%)$ have answered 72 hour pill for the reason behind using Emergency contraceptives.

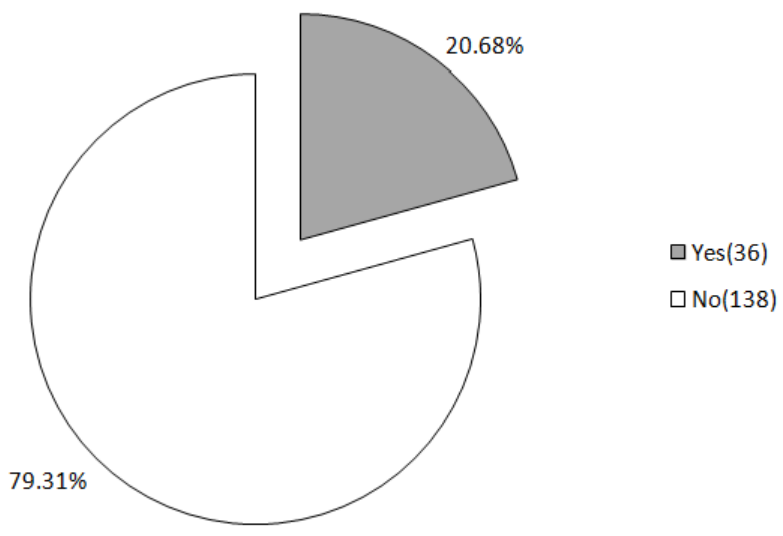

Figure 4: Use of emergency contraceptives

Pie Chart above shows that out of 174 respondents, 36(20.68\%) have used Emergency contraceptives while remaining $138(79.31 \%)$ have not used it yet. 


\section{Demographic data}

Maximum number of respondents in the study belongs to 20-40 years age group. More than half i.e. $54.63 \%$ had married at the age of 10-20.only around 9\% were illiterate. Female respondents were more (61.21\%) than male $(38.78 \%)$.

\section{DISCUSSION}

Study findings have been discussed in terms of objectives stated and with the findings of other similar studies.

Present study showed maximum awareness regarding Family Planning, 393(95.85\%) respondents out of 410 had some knowledge about it. A study done by $\mathrm{H}$ Tuladhar and $\mathrm{R}$ Marahatta also revealed a high percentage of awareness in family planning methods, $93.0 \%$ of the respondents knew about at least one method ${ }^{5}$. T.V/Radio was found to be the major source of information regarding family planning. Again the study by $\mathrm{H}$ Tuladhar and $\mathrm{R}$ Marahatta stated mass media the main source of knowledge as reported by more than half (55.5\%)of the respondents. Most of other studies also have stated print and electronic media to be the common source of public awareness ${ }^{5}$.

In the present study maximum number of respondents had an idea about Depo-Provera injection, condom, and pills respectively. A study by Tanabe et al. reveals that $76.8 \%$ of married women reported that they were aware of any modern method compared to $64.9 \%$ of unmarried women .Women who ever attended school were more likely to report that they were aware of any modern method compared to those who never attended school ${ }^{6}$. Only 277 (70.48\%) respondents said that they have been using or have used at least one family planning measure and 152(54.87\%) out of 277 have been using Depo (Modern measure) for family planning. Among temporary methods of family planning, condom was most commonly used i.e. $64 \%$. Less than half of the respondents (44\%) had already done vasectomy as permanent methods of $\mathrm{FP}^{7}$. While a study by Atuahene et al. revealed most (88.2\%)used injectable, only $6.1 \%$ and $0.9 \%$ used Implants and IUD, respectively ${ }^{8}$. Nepal Fertility, Family Planning and Health Survey reported that $29 \%$ of women said that they would

\section{Age of the respondents}

\begin{tabular}{|c|c|c|}
\hline Age group & Number & Percentage \\
\hline $10-20$ & 19 & $4.60 \%$ \\
\hline $20-30$ & 144 & $35.12 \%$ \\
\hline $30-40$ & 123 & $30 \%$ \\
\hline $40-50$ & 85 & $20.73 \%$ \\
\hline $50-60$ & 30 & $7.31 \%$ \\
\hline $60-70$ & 09 & $2.19 \%$ \\
\hline
\end{tabular}

\section{Age at marriage}

\begin{tabular}{|c|c|c|}
\hline Age group & Number & Percentage \\
\hline $10-20$ & 224 & $54.63 \%$ \\
\hline $20-30$ & 176 & $42.92 \%$ \\
\hline $30-40$ & 10 & $2.43 \%$ \\
\hline
\end{tabular}

\section{Literacy of respondents}

\begin{tabular}{|c|c|c|}
\hline Educational level & Number & Percentage \\
\hline Illiterate & 37 & $9.02 \%$ \\
\hline Primary & 92 & $22.43 \%$ \\
\hline Lower secondary & 129 & $31.46 \%$ \\
\hline Higher secondary & 152 & $37.07 \%$ \\
\hline
\end{tabular}

\section{Sex of respondents}

\begin{tabular}{|l|c|c|}
\hline Sex & Number & Percentage \\
\hline Male & 159 & $38.78 \%$ \\
\hline Female & 251 & $61.21 \%$ \\
\hline
\end{tabular}


prefer female sterilization followed by $27 \%$ women preferring injectable and $18 \%$ preferring pills ${ }^{9}$. Even a prevalence of family planning method use in post-partum period was studied in Ethiopia by Gebremedhin et al. and found it to be $80.3 \%{ }^{10}$. Around one-fourth of aware respondents (29.51\%) were not using any family planning measure and 36 non-users (31.03\%) answered that they didn't need till date. Also $17.24 \%$ non-users confessed that they didn't like using any contraceptives. When asked of reasons for not using FP services in the study of Mishra $\mathrm{SR}$, Joshi MP and Khanal V; lack of knowledge about availability of FP services $(20.0 \%)$, lack of resources to access $(8.6 \%)$ and fear of stigma and discrimination (14.3\%) were the major ones mentioned. The other reasons for not using FP services were having irregular sexual partners, being unmarried/single and illness ${ }^{11}$. Likewise, the qualitative findings also indicate fear of contraceptives' side effects as a barrier to use contraception by women $^{12}$.

Societal influence, which can affect one's behaviour, was a major factor contributing to women's use of contraceptives for FP. Nine of the 12 studies found male influence to be the strongest factor in women's decisions to utilize FP services. Some of the reasons males were against contraceptive use were connected to misperceptions and mistrust of "western" influence ${ }^{13}$. Nepali women who start using the pill or DepoProvera are likely to use it for a relatively short period of time. Within 24 months of starting to use the pill, almost 60 percent of users have stopped using the method ${ }^{14}$. According to recent NDHS data, nearly two-thirds of women who were not using or do not intend to use contraception gave fertility-related reasons - infrequent sex, menopause, sub fecund/in-fecund and desire for more children ${ }^{15}$ In our current study, $134(48.37 \%)$ responded convenient use as the reason for using particular family planning measures. The other study in eastern Nepal by Keyal NK and Moore M reflect that DMPA was the most popular contraceptive, followed by condoms. The only other common option chosen was the combined pill. Of DMPA users, $88 \%$ said that they chose it because it as convenient. $50 \%$ of condom users stated that they chose them because they were safe and $39 \%$ found them convenient. $11 \%$ said the method was easily reversible. Among combined pill user, $38 \%$ found it convenient and $38 \%$ said it was their husband's choice. The remainder used it because they did not experience bleeding problems during use ${ }^{16}$.

In the current study, 174(42.43\%) out of 410 had knowledge regarding Emergency contraceptives. Two-third stated it as 72 hour pill. Out of 174 respondents, 36(20.68\%) had used Emergency contraceptives while remaining 138(79.31\%) had not used it yet. Use of emergency contraception and abortion are increasing steadily in Nepal. Both methods prevent unwanted pregnancies in certain circumstances, therefore are essential components of reproductive health. However, this increase is a sign of failure of the family planning programme. It is not wise to use emergency contraception and abortion as alternatives to family planning methods. The FP programme should therefore develop a strategy to increase awareness about the importance of FP to prevent unwanted pregnancies and discourage the use of emergency contraception and abortion as a method of $\mathrm{FP}^{17}$.

In thousands of households, hostility towards family planning has its roots in deep-rooted customs and beliefs. In Nepal's largely patriarchal culture, it remains the norm for couples to have four or more children: preference for sons means women are forced to go on having children until boys are born. Contraception remains an alien, uncomfortable idea for millions of Nepalese and is tightly controlled by men: women often need consent from their husbands to use contraception ${ }^{18}$.

214 million women of reproductive age in developing countries who want to avoid pregnancy are not using a modern contraceptive method. Evidence suggests that women who have more than 4 children are at increased risk of maternal mortality ${ }^{19}$.

\section{CONCLUSION}

Maximum number of respondents had at least some basic information regarding family planning. Mass media was the major source of information to them. Depo-Provera and condom were the contraceptives used by maximum of respondents respectively and convenience in using was revealed as the reason for use of these measures. Though $95 \%$ of respondents had knowledge regarding family planning, only $70.48 \%$ were using contraceptives but still it is above than the National contraceptive prevalence rate. About two-fifth of the respondents were aware about emergency contraceptives and around $10 \%$ of respondents had used it at-least once. Awareness level is satisfactory but use of family planning measures can still be increased to ensure the prosperity and health of the family. Various community level programs can be done to increase the knowledge depth regarding family planning and its importance.

\section{REFERENCES}

1. FPAN [Internet].Introduction. Available from: http://www.fpan.org/.

2. Wiki [ Internet]. Available from: https://en.wikipedia.org/wiki/Family_planning.

3. Nepal Demographic Health Survey, 2016.

4. Words in the Bucket [Internet].McMahon Claire. Importance of Family Planning;2017 July 20. Available from: https://www.wordsinthebucket.com/the-importance-of-familyplanning.

5. Tuladhar H,Marahatta R. Awareness and practice of family Planning methods in women attending Gyne OPD at Nepal Medical College Teaching Hospital.NMCJ.2008;10(3):184-191.

6. Tanabe M, Myers A, Bhandari P, Cornier N, Doraiswamy S, Krause $\mathrm{S}$. Family planning in refugee settings: findings and actions from a multi-country study. Conflict and health.2017;11:9.

7. Sharma D. Kafle R. An exploratory study on knowledge and practice regarding family planning and immunization among 
women attending MCH clinic. Int J Sci Rep. 2017 Jun;3(6):156165.

8. Atuahene M D, Afari E O, AdjuikM, Obed S. Health knowledge, attitudes and practices of family planning service providers and clients in Akwapim North District of Ghana. Contraception and Reproductive Medicine.2016;1:5.DOI:10.1186/s40834-0160016-3.

9. Sigdel A, Alam M, Bista A, Sapkota H, Ghimire B S. Knowledge and Utilization of Family Planning Measures in a Muslim Community of Sunsari District, Nepal .IJIR. 2016;2(8):359.

10. Gebremedhin A Y, Kebede Y, Gelagay A A, Habitu Y A. Family planning use and its associated factors among women in the extended postpartum period in Addis Ababa, Ethiopia. Contraception and Reproductive Medicine.2018; 3:1. DOI 10.1186/s40834-017-0054-5.

11. Mishra SR, Joshi MP, Khanal V. Family Planning Knowledge and Practice among People Living with HIV in Nepal. PLoS ONE. 2014 Feb;9(2): e88663.doi:10.1371/journal.pone.0088663.

12. Tilahun $\mathrm{T}$, Coene $\mathrm{G}$, Luchters $\mathrm{S}$, Kassahun W, LeyeE, Temmerman M, Degomme O. Family Planning Knowledge, Attitude and Practice among Married Couples in Jimma Zone, Ethiopia. PLoS ONE .2013;8(4): e61335. doi:10.1371/journal.pone.0061335.

13. Ackerson $\mathrm{K}$, Zielinski R. Factors influencing use of family planning in women living in crisis affected areas of Sub-Saharan Africa: A review of the literature. Midwifery. 2017;54:35-60.Available from:www.elsevier.com/locate/midw

14. Engender Health. Contraceptive Use and Discontinuation Patterns in Nepal: Norplant, IUCD, Pill, and Injectables. 2003 Sep.Available from: http://www.engenderhealth.org

15. CREHPA. The Status of Family Planning and Reproductive Health in Nepal.UNFPA-ICOMP Regional Consultation.

16. Keyal NK, Moore M. Contraception in Eastern Nepal: A study of knowledge and use. JUCMS.2014;2(6):15-20.

17. Shrestha DR, Shrestha A, Ghimire J. Emerging Challenges in Family Planning Programme in Nepal. JNHRC. 2012 May;10(21):108-12.

18. Breaking through barriers to family planning in $21^{\text {st }}$-century Nepal. IPPF. 2015 [cited on 6 july 2015] Available from: https://www.ippf.org.

19. Family planning/Contraception. WHO.2018[cited on: 8 february 2018] Available from: https://www.who.int. 